\title{
Assistive Technologies: Saviour of Mathematics in Higher Education
}

\author{
Pritika Reddy ${ }^{1 *}$, Emmenual Reddy ${ }^{2}$, Vishal Chand ${ }^{2}$, Sione Paea ${ }^{2}$ and Avinesh Prasad ${ }^{2}$ \\ ${ }^{1}$ Department of Computing and Information Systems, Fiji National University, Suva, Fiji, ${ }^{2}$ School of Technology, Engineering, \\ Mathematics and Physics, The University of the South Pacific, Suva, Fiji
}

OPEN ACCESS

Edited by:

Shriram Raghunathan,

VIT University, India

Reviewed by: Armando Maciel Toda, Universidade de São Paulo-São

Carlos, Brazil

Michael Chen,

York University, Canada

Carla Santos Pereira,

Infante D. Henrique Portucalense,

Portugal

*Correspondence:

Pritika Reddy

pritika.reddy@fnu.ac.fj

Specialty section:

This article was submitted to Mathematics of Computation and

Data Science,

a section of the journal

Frontiers in Applied Mathematics

and Statistics.

Received: 21 October 2020 Accepted: 28 December 2020

Published: 05 February 2021

Citation:

Reddy P, Reddy E, Chand V, Paea S and Prasad A (2021) Assistive

Technologies: Saviour of Mathematics

in Higher Education.

Front. Appl. Math. Stat. 6:619725.

doi: 10.3389/fams.2020.619725
The pervasion and inclusion of new technologies into teaching and learning processes are continuously changing the higher education landscape. Selected and specific technologies termed as "assistive technologies" are being used as key tools for enabling students to access education and actively and independently participate in the education process, improving learning and supporting inclusive education. This paper presents students' perception of the use of various assistive technologies such as mobile learning, tablet learning, lecture capture, gamification, and online intelligent systems that have been developed for learning and student support at a higher education institute. There is also a broad discussion on how these can be adopted and adapted in mathematics learning in higher education. It is well documented that students have low-esteem toward or while doing the subject and have math phobia, particularly in higher education. An online questionnaire on the students' perception of using assistive technologies was deployed to the mathematics students. The results show that assistive technologies are indeed a saviour of mathematics with a significantly positive attitude garnered toward using them for learning mathematics.

Keywords: mathematics, assistive technology, higher education, inclusive education, higher education in Fiji

\section{INTRODUCTION}

The unprecedented challenges presented by COVID-19 have changed the world of learning, causing disruptions to the delivery of learning strategies leading most countries to rethink education services and pedagogies to ensure equitable access to inclusive and quality learning. Not surprisingly, an immediate or emergency response from the education institutes was a shift to Emergency Remote Teaching (ERT) using online platforms that have become the new reality and norm of global learning in the current crisis of COVID-19 [1]. According to [2], ERT is a temporary shift of instructional delivery to an alternate delivery model due to crisis circumstances that involve fully remote teaching solutions for learning. The authors also mention that ERT needs to be thoughtfully designed using dimensions such as modality, pacing, student-instructor ratio, pedagogy, instructor role, student role, communication synchrony, the role and type of assessments, and source of feedback. The Internet and assistive technologies (ATs) are mandatory for courses offered in ERT and online mode [1,2]. The ATs can also be referred to as key tools or devices that enable students to access ERT courseware, participate actively in the education process, and support inclusive education [3], for example, remembering lectures, solving problems, aligning tasks, writing, and managing, storing, and retrieving information $[4,5]$. AT is widely used to ensure appropriate educational opportunities to all students, including students with learning disabilities [3,6], at-risk students [7-10], and gifted and talented students [11]. 
During COVID-19, there has been an unprecedented growth in the usage of ATs from education institutes in developed countries. However, many educational institutes from developing countries, including those in the Pacific region, have revealed that they are not ready to provide ERT $[2,12]$. The literature records challenging factors such as untrained facilitators [9, 13], lack of proper infrastructure [9, 14, 15], a wide range of ICT and digital competencies of students [10, 16-20], and poor academic background [7]. The challenge is magnified multiple times when it comes to learning mathematics amidst the factors mentioned above.

To better comprehend the situation from a Pacific perspective, this study aims to evaluate the effectiveness of different ATs in learning mathematics in higher education. Assistive technologies can assist teachers and instructors in meeting the challenges they face in the teaching and learning process, which is even more pronounced with student diversity [11]. For example, a range of attitude, self-confidence, and problem-solving skills are more challenging to handle in a classroom. However, according to [3], the use of ATs can enhance mathematics instruction to increase student interest, engagement, and thus success in the discipline. The use of ATs in mathematics education will only be successful and effective if all the facilitators of mathematics have relevant competencies and are confident in using the ATs themselves. Facilitator training is an important factor in the successful use of ATs for mathematics education; therefore, relevant professional training should be the major focus of the stakeholders [21].

Different ATs can help students to improve their mathematics skills in all learning purposes $[11,21,22]$. The ATs such as lecture capture, online videos, mobile apps, and tablets have been identified as the most commonly used tools for educational purposes in mathematics [11]. One of the initiatives at the University of the South Pacific (USP) is the Online Mathematics Diagnostic Tool (OMDT) to bridge the mathematics knowledge gaps in students' transition from secondary to tertiary education $[7,8]$, which has been made mandatory for all freshmen entering into the degree programs. Significantly, the current COVID-19 pandemic demands students to adopt the available AT to facilitate communication, data acquisition, research, and administration to remain academically productive [1].

Mathematics curriculum and instruction continue to be a challenge to all facilitators who require proper planning to use ATs to improve the learning of mathematics. Students' difficulties while studying mathematics can be reduced with ATs if appropriately implemented [11, 21, 22]. The literature also records that the ATs help improve and guide students' performance by providing them with reliable information on learning aptitude and generic knowledge and skill [23-25]. The authors in $[26,27]$ argue that although ATs are well known to improve users' learning, appropriate and relevant ATs in the right learning context are important. They also state that, in the $21^{\text {st }}$ century, the educators and users of ATs also need to have relevant digital literacy competencies to exploit resources using the ATs. The authors in $[26,28]$ claim that the number of digital instruments or ATs for learning is increasing which provides easier access to learning resources. However, the use of ATs will only be rewarding if the students are willing to use them for their learning.

According to [10,13, 16, 29-32], the success of any technology used for learning or education purposes lies in the student attitude, perception, willingness, and readiness to use them for their learning. In the Pacific context, the use of ATs for learning is still an upcoming approach for education at all levels. While there has been concrete effort to deploy specific ones such as tablets in Tuvalu [17] and USP [19], we do not have cases specifically for learning or support in mathematics. The challenge for the educators of mathematics in the Pacific is to firstly deliver and then to improve students' mathematics skills using appropriate AT $[33,34]$. Hence, this study intends to evaluate students' attitudes and perceptions toward the use of ATs for mathematics education.

The current study provides baseline data on the use of ATs for improving mathematics learning in higher education in the South Pacific context. The results can help educators identify the most effective AT that can be used for the learning of mathematics. The results from student perception will provide a clear indication on the ATs they are aware of and ones they prefer to use, and how these benefit them in learning mathematics. Such information can be used by the educators to integrate appropriate ATs for improving the learning of mathematics. In the present study, the discussion on the use of ATs is as follows: the definitions and importance of ATs for education and mathematics is reflected in Literature Review, Results and Analysis outlines the method of data collection, and the results which consists of student perception and attitude toward the use of various ATs identified for this study are reflected in Discussion.

\section{LITERATURE REVIEW}

Mathematics is a challenging area, and mathematics learning can be supported using ATs through easy access to learning materials, active participation in class, and the achievement of academic goals [35]. ATs are defined as commercially acquired equipment used to enhance or maintain individuals' functional capability with a disability [36-38]. The authors [11] define ATs as items, tools, or products made by teachers, designed to improve students' functional abilities. According to [38, 39], AT can be classified as low, medium, or high technology. Low technology devices are less sophisticated and inexpensive tools that are easy to use, such as book holder, braille text, color filters, markers, pencil grip, keyguard, and weighted pen. The mid-tech devices are like battery-operated devices or simple electronic devices such as books on tape, electronic spell checkers, portable keyboard, and word processors. Finally, the high-tech devices involve complex electronics and usually contain micro-computer components for storage and retrieval of expensive tools, for example, prediction software, talking calculators, and hearing aids or listening devices. The authors [37-39] state that ATs are used to motivate and provide learning opportunities and enable students to accomplish whatever was not possible before. In this era, the technological innovations have made it possible for experts to develop ATs that 
can also assist people with disabilities in their learning processes. For example, ATs developed to assist people with visual and hearing impairments, individuals with learning disabilities, and physically disabled people [37, 38].

Technology-mediated ATs, which are designed to improve students' capabilities in learning mathematics, are more common nowadays [36, 38]. These ATs provide more engaging demonstrations of mathematical concepts and skills and articulate ways to solve mathematical problems through virtual teachers thinking aloud. It provides students with frequent, individualized opportunities to engage in interactive mathematical tasks and activities [35, 40, 41]. The mathematics curriculum requires problem-solving, reasoning, and problem formulation. ATs can be useful if used appropriately to foster all students [11]. Few selected assistive technologies that have been developed for improving mathematics learning include the following:

i. Abacus Media for Visually Impaired Students, AudioBased Mathematical Learning Tools, Interactive Media Learning Design of Full-Audio CD, and Mathematical Learning [36].

ii. Incorporation of games [37].

iii. Tablet-mediated learning [35].

iv. RekenTest (RT) software for students with hearing disabilities [5].

v. Online Mathematics Diagnostic Tool (OMDT) [8].

vi. Digital learning assistant [41].

vii. Mathematical Braille [42].

viii. MathPad Plus, ViewPlus Accessible Graphing Calculator, GTCalc Scientific Calculator, Talking Texas Instruments, MathTalk, and Techtrekers [11].

According to researchers, although technology-mediated learning has been there since the 1970s [37], technology and mathematics are two different subjects and have different competency requirements [41]. For technology-mediated ATs to be successfully integrated into the learning of mathematics, student attitude, perception, and readiness matter [10, 17, 32, 43]. The authors $[16,44]$ state that, in technology-mediated ATs learning, student competencies and self-efficacies play a vital role in the continuous use of technology in the learning process. According to [39], student competencies and self-efficacy

TABLE 1 | Description of the data set.

\begin{tabular}{ll}
\hline Variables & \multicolumn{1}{c}{ Description } \\
\hline V1 & Lecture capture video recordings \\
V2 & Satellite tutorial using REACT videoconferencing \\
V3 & Big blue button (remote teaching tool) BBB \\
V4 & Online Mathematics Diagnostic Tool (OMDT) \\
V5 & Tablets \\
V6 & Mobile device \\
V7 & Interactive whiteboard \\
V8 & Simulation games \\
V9 & Mathematics software, e.g., Mathematica, Matlab, R, SPSS \\
V10 & Online video, e.g., YouTube, Khan's academy
\end{tabular}

regulate the students' learning and performance. Hence, they are motivated to participate in their environment using relevant assistive technologies actively. The authors [45] add that the most important factor contributing to the continuous use of ATs is the student self-confidence which lets them decide which AT to use and how to use it.

Therefore, the authors of this paper believe that students' perceptions of using ATs must be measured so that stakeholders and educators have a deeper understanding of ATs in learning mathematics. From the research presented in the literature, the students perceived the use of ATs as follows:

i. It made the learning activities fun, engaging, and useful and increases their self-confidence [46].

ii. It promoted the learning of mathematics, reduced the anxiety students had for mathematics subject, and improved student's problem-solving skills in mathematics $[47,48]$.

iii. It fostered strong positive mentality and confidence among mathematics students and promoted self-directed mathematics learning [41, 45, 48].

iv. It helped engage the students in the learning process, allowed them to have higher accuracy with computational tasks, helped create a less-anxious mathematics environment for students, motivated students, and helped them get a deeper understanding of the mathematical content $[48,49]$.

In the South Pacific, the USP has integrated a number of ATs in their teaching and learning processes that are assisting its students in learning and supporting mathematics. The students use ATs such as lecture capture, big blue button, satellite tutorial, tablets and mobile devices, simulation games, mathematics software, and online videos in mathematics courses at the university [7, 15]. Another new AT developed at the university is Online Mathematics Diagnostic Tool (OMDT), which improves students' mathematics skills at the university $[8,15]$. This intervention is a compulsory module that the first-year students have to attempt to improve their numeracy skills at the university. The current paper presents the results of students' perception of using identified ATs at the university in the mathematics courses. Since this study is first of its kind, the results will enable the educators from the higher education institutes and beyond to make appropriate decisions while using the relevant ATs to facilitate ERT and online mathematics courses.

\section{RESEARCH OBJECTIVES}

The study aims to evaluate students' perspectives on the use of different assistive technologies identified in this study for the learning of mathematics.

\section{METHODOLOGY}

The research methodology for this study is quantitative, whereby the research design follows a survey methodology. 
TABLE 2 | Course information.

\begin{tabular}{|c|c|c|c|}
\hline Course & Course description & Sample participated & Year of study \\
\hline MA111F (face-face) & Calculus and linear algebra & 77 & Year 1 \\
\hline MA1110 (online) & Calculus and linear algebra & 67 & Year 1 \\
\hline MA211F (face-face) & Advanced calculus & 36 & Year 2 \\
\hline MA2110 (online) & Advanced calculus & 12 & Year 2 \\
\hline MA313F(Face-face) & Real and complex analysis & 20 & Year 3 \\
\hline
\end{tabular}

Since this is the very first study done on the use of assistive technology and the students' perception of using them, the authors decided to use a survey to collect the data. Using survey methodology enabled the authors to collect information regarding the attitude and satisfaction of the students toward using the assistive technologies for their learning. The students were given an online questionnaire which was designed using a 5-point Likert scale as follows: "Strongly Disagree = 1", "Disagree = 2", "Neutral = 3", "Agree $=4$ ", "Strongly Agree $=5$ ". The students were to rate the following questions about the assistive technologies: how effectively and frequently they had used the assistive technologies for their learning, what their perceptions were of using the three most common assistive technologies at USP (big blue button, satellite video conferencing, and lecture capture recording), and their overall perception of using the ten chosen assistive technologies for this study (shown in Table 1). A pilot study was conducted with a sample of 30 students to test the validity and reliability of the questionnaire. The Cronbach alpha value for the pilot study was 0.94 which indicated that the questionnaire was valid and reliable for the study.

The authors then administered the questionnaire to the students who were enrolled in the mathematics courses at USP. The courses chosen are shown in Table 2 .

The Moodle message, course announcement via Moodle, and email distribution were used to inform the students about the survey. The students were given one week to fill the questionnaire. The students took a maximum time of $15 \mathrm{~min}$ to fill in the questionnaire. The students' responses to the online questionnaire were automatically saved in Moodle. The survey captured student views on various ATs that are used at the USP. The student's responses were voluntary and confidential. All responses were compiled and analyzed in groups. The participants' details were anonymous, and the responses were only used for analysis purpose for this study. The SPSS software was used to carry out the descriptive analysis. The data set for the study is shown in Table 1 and Table 3.

The demographics of the sample is displayed in Figure 1. In total, 185 students participated in the survey with $64.4 \%$ being males and $35.65 \%$ being females indicating that mathematics as a subject is male dominated. The students were enrolled at various campuses as shown in Figure 1 with the majority of students participating from Laucala Campus based in Suva, Fiji. The age group of the students was 17 years and above with $60 \%$ of the participants falling in the range of 17-22 years.

\section{RESULTS AND ANALYSIS}

This section of the paper details the results captured from the online survey on the students' perception of the use of different ATs in learning mathematics at the USP.

Question 1. Have you effectively used each of the following Assistive Technologies in your courses?

The literature shows many different types of ATs used for educational purposes. However, only certain ones such as lecture capture, online videos, and tablets have been effectively used in mathematics [11]. For this paper, the ATs used for mathematics learning were lecture capture, satellite tutorial, BBB, OMDT, tablet, mobile device, interactive whiteboard, simulation game, mathematics software, and online video. Table 4 shows the response from students on the use of given ATs for learning for five mathematics courses chosen for the current study. For

TABLE 3 | Description of the second data set.

U1

U2

U3

U4

U5

U6

U7

U8

U9

U10
The use of assistive technology for learning mathematics is important The use of assistive technology enhances communication and collaboration Assistive technology makes the content of teaching material more attractive Assistive technology enhances the learning methodologies in math Assistive technology makes us better understand the concepts in mathematics Assistive technology helps us learn concepts using our learning preferences Assistive technology helps us learn concepts using our learning style Assistive technology promotes self-esteem and reduces the negative perception of mathematics Assistive technology can assist me to improve my performance in mathematics Assistive technology has improved my performance in mathematics 


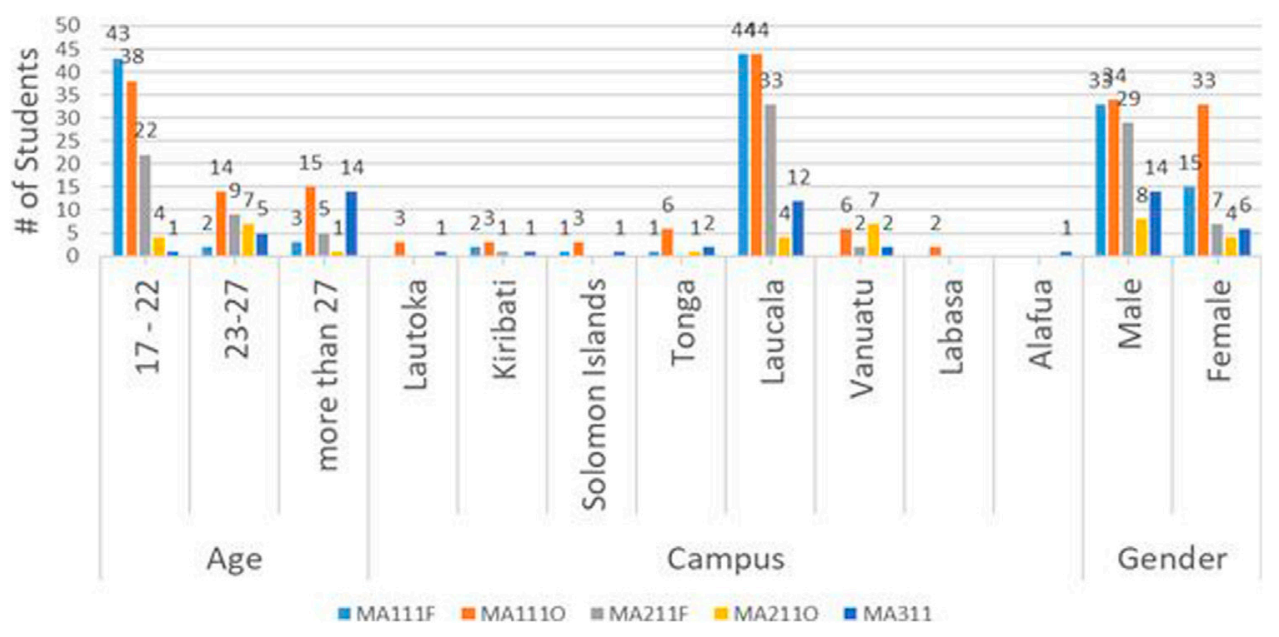

FIGURE 1 | Participants' demographics.

MA313F, the most effectively used AT was lecture capture followed by the online videos. For MA211O, the students' responses are neutral for all the ATs except V10-online videos. For $\mathrm{MA} 211 \mathrm{~F}$ mode, students had mixed reactions overall-their perception varied according to different ATs. For V1 (lecture capture), V6 (mobile device), V9 (mathematics software), and V10 (online videos), they perceived that the ATs were effective and assisted them with the learning of mathematics. For the rest of the ATs, the perception was neutral.

For MA 111O, the students preferred online videos followed by the use of mobile phones and then lecture capture. The preference for mobile phones and lecture capture was higher compared to the other ATs. In MA111F, the most effective ATs were the online videos, lectures capture recordings, and mathematics software. For this course, there are weekly labs, and students use Mathematica software. Once again, for the other ATs, the response on the effectiveness was neutral. However, for the overall mean of responses from the students on how effectively they have utilized the ATs in their courses, the response was neutral. This means that some students are more aware of the ATs when compared to the others. Therefore, it becomes the responsibility of the facilitator to mentor the students when implementing the ATs as part of their courses $[13,50]$. This is also the responsibility of the institution to ensure that the students (and we as the staff) are ready to move to ERT and online mode of delivery during crises and emergencies such as the COVID-19.

From the trend shown by the five courses, the two most effectively used ATs were online videos and lecture capture. According to prior studies, students prefer lecture capture as it allows them to pause, play, and rewind lecture videos plus they can revisit and seek clarification on complex topics. This allows learning to take place at their own pace and time and as a result improves their performances [50-52]. However, the researchers

TABLE 4 | Students' use of the ATs for the mathematics courses. The highlighted shows the mean responses for each course with each AT used in the courses.

\begin{tabular}{|c|c|c|c|c|c|c|c|c|c|c|c|}
\hline MA313F & V1 & V2 & V3 & V4 & V5 & v6 & V7 & v8 & v9 & V10 & Overall \\
\hline Mean & 4.25 & 3.75 & 3.55 & 3.35 & 2.90 & 3.60 & 3.15 & 2.65 & 3.75 & 4.15 & 3.51 \\
\hline Std. deviation & 1.20 & 1.16 & 1.31 & 1.34 & 1.48 & 1.69 & 1.53 & 1.46 & 1.44 & 1.22 & \\
\hline MA211F & $\mathrm{V}_{1}$ & V2 & V3 & V4 & V5 & V6 & V7 & V8 & V9 & V10 & \\
\hline Mean & 4.33 & 3.36 & 3.83 & 3.69 & 3.61 & 4.36 & 3.41 & 3.00 & 4.19 & 4.52 & 3.83 \\
\hline Std. deviation & 0.79 & 1.29 & 1.21 & 1.09 & 1.27 & 0.99 & 1.20 & 1.09 & 0.92 & 0.84 & \\
\hline MA111F & V1 & V2 & V3 & V4 & V5 & V6 & V7 & V8 & V9 & V10 & \\
\hline Mean & 4.04 & 3.48 & 3.75 & 3.84 & 2.94 & 4.10 & 3.35 & 3.27 & 4.01 & 4.34 & 3.712 \\
\hline Std. deviation & 1.11 & 1.23 & 1.19 & 1.23 & 1.40 & 1.20 & 1.30 & 1.29 & 1.09 & 1.02 & \\
\hline Overall mean for F2F courses & 4.20 & 3.53 & 3.71 & 3.62 & 3.15 & 4.02 & 3.30 & 2.97 & 3.98 & 4.33 & 3.68 \\
\hline MA2110 & V1 & V2 & V3 & V4 & V5 & V6 & V7 & V8 & V9 & V10 & \\
\hline Mean & 3.75 & 3.25 & 3.41 & 3.25 & 3.08 & 3.33 & 3.00 & 2.91 & 3.16 & 4.00 & 3.31 \\
\hline Std. deviation & 1.35 & 1.35 & 1.08 & 0.96 & 1.37 & 1.37 & 1.12 & 0.99 & 1.33 & 1.12 & \\
\hline MA1110 & V1 & V2 & V3 & V4 & V5 & V6 & V7 & V8 & V9 & V10 & \\
\hline Mean & 4.27 & 4.03 & 3.46 & 3.70 & 3.42 & 4.28 & 3.43 & 3.27 & 3.49 & 4.39 & 3.77 \\
\hline Std. deviation & 0.978 & 0.953 & 1.105 & 1.10 & 1.24 & 0.93 & 1.20 & 1.16 & 1.18 & 1.01 & \\
\hline Overall mean for online courses & 4.01 & 3.64 & 3.43 & 3.47 & 3.25 & 3.80 & 3.21 & 3.09 & 3.32 & 4.19 & 3.54 \\
\hline
\end{tabular}

The Likert scale used was "Strongly Disagree = 1", "Disagree = 2", "Neutral = 3", "Agree = 4", and "Strongly Agree = 5". 
TABLE 5|Frequency of the ATs used by the students. The frequency is greater than 6 as students access the ATs for at least $1 \mathrm{~h}$ each day to complete their tasks. Therefore, the minimum hours for this study is $6 \mathrm{~h}$.

\begin{tabular}{|c|c|c|c|c|c|c|c|c|c|c|c|}
\hline MA313F & V1 & V2 & V3 & V4 & V5 & V6 & v7 & V8 & V9 & V10 & Overall \\
\hline$>6$ h (\%) & 75 & 50 & 50 & 40 & 50 & 65 & 30 & 35 & 60 & 85 & 54 \\
\hline MA2110 & $V_{1}$ & V2 & V3 & V4 & V5 & V6 & V7 & V8 & V9 & V10 & \\
\hline$>6$ h (\%) & 66.66 & 33.33 & 50 & 25 & 50 & 58.33 & 25 & 16.66 & 50 & 66.66 & 44 \\
\hline MA211F & V1 & V2 & V3 & V4 & V5 & V6 & V7 & V8 & V9 & V10 & \\
\hline$>6$ h (\%) & 80.55 & 30.55 & 52.77 & 8.33 & 47.22 & 83.33 & 33.33 & 16.66 & 72.22 & 94.44 & 52 \\
\hline MA1110 & V1 & V2 & V3 & V4 & V5 & V6 & V7 & V8 & V9 & V10 & \\
\hline$>6$ h (\%) & 41.79 & 41.79 & 23.88 & 23.88 & 31.34 & 73.13 & 34.32 & 14.92 & 43.28 & 77.61 & 41 \\
\hline MA111F & V1 & V2 & V3 & V4 & V5 & V6 & V7 & V8 & V9 & V10 & \\
\hline$>6$ h (\%) & 59.74 & 32.46 & 41.55 & 23.33 & 23.37 & 71.42 & 31.16 & 18.18 & 57.14 & 81.81 & 44 \\
\hline Overall (\%) & 63.91 & 36.77 & 43.29 & 23.96 & 37.55 & 70.44 & 30.83 & 19.93 & 56.63 & 81.22 & 47 \\
\hline
\end{tabular}

in [12] have stated that students prefer online videos more compared to the lecture capture videos because the online videos were more interactive and more comfortable to understand and follow when compared to the lecture capture videos. For the other ATs which were not so popular, the authors of this paper feel that there needs to be more awareness about them, and guidelines regarding their use should be availed to the students. According to $[12,53,54]$, students' views on ATs are dependent on their knowledge about the relevant AT and their skills in using the AT given to them. Hence, when an AT is implemented in a course, proper guidelines on its usage must be provided to the users.

Question 2. How frequently have you used each of the following Assistive Technologies in your courses?

For this question, the results are for all the ATs accessed more than 6 times per week. The authors have taken six as the minimum number of times the student accessed the AT per week since per week a student has to dedicate $12 \mathrm{~h}$ to a particular course meaning a total of $180 \mathrm{~h}$ of self-learning in a course per semester. Therefore, the cut-off is $6 \mathrm{~h}$ which means a student should at least access an AT 6 times per week.

Table 5 shows the frequency of the ATs used by the students per week. From the results displayed, V10 (online videos) and V1 (lecture capture) were the most frequently used ATs for MA313F and MA211O. The students' preference is similar to prior studies conducted where students utilized more of the mentioned ATs for their learning purposes [12, 50, 52]. Prior studies show that students prefer videos as they help the students to recap on their materials, and the views of the videos are higher during the exam times [52]. For MA211F, MA111O, and MA111F, V6 (mobile phone) was the second most used AT followed by lecture capture. The overall mean results show that online videos were most commonly used by the students, followed by mobile phones and then lecture capture. Moreover, on average, around $50 \%$ enrolled in mathematics courses accessed and used the ATs in their courses for more than $6 \mathrm{~h}$ per week. The use of mobile devices as an AT is common because students have access to it or own it; hence, they can access the course materials from anywhere at any time. The students are in control of their learning process and reduce the challenges faced by students with special needs [55]. The notion of integrating mobile phones/ smartphones into online learning seems to be most effective for the students at USP. This claim is supported by [10, 17, 43, 56] which states that nowadays students prefer their mobile phones for learning, and this is relevant to the South Pacific as well.

Question 3: Which device have you used to access each of the following Assistive Technologies in your courses?

For the five mathematics courses, the laptops and mobile phones are the most commonly used devices to access the ATs selected for this study. Figure $\mathbf{2}$ shows that the numbers are more than the sample size for each course; it means that students may have used more than one type of device to access the ATs. It is also interesting to note that the students have used their mobile phones more than the desktops, and the students had used tablets for their learning process in mathematics. The results do relate to prior studies that have been conducted in the South Pacific by [7, 10, 57] which revealed that the mobile devices such as tablets and mobile phones were becoming a standard learning tool in higher education. The literature also shows that students prefer smartphones because they boost their confidence and allow self-directed learning, and the interface of these smart devices makes learning more interesting $[10,43,56]$.

1. Student perspective on lecture capture recordings, $\mathrm{BBB}$, and satellite tutorial for MA111O, MA111F, MA211O, MA211F, and MA313F

Table 6 shows the summarized version of the students' perspective of the most commonly used ATs at the USP. The detailed results for each AT are in the Appendix which consists of 10 variables with student perception ranging from "Strongly Disagree $=1$ ", "Disagree $=2$ ", "Neutral $=3$ ", "Agree $=4$ ", to "Strongly Agree $=5$ ". Student perception plays a vital role in the continuous use of technology for learning [10, 16, 17, 21, 58]. Since the use of ATs has proven to be effective for learning mathematics [51], this study evaluated the students' perspective on the commonly used ATs in the mathematics courses at USP. The mean values for the three ATs round up to 4-4.5 which means that the students agreed that the use of lecture capture, satellite tutorial, and BBB was important. It also enhanced communication and collaboration, enhanced the learning processes in mathematics, allowed students to learn 


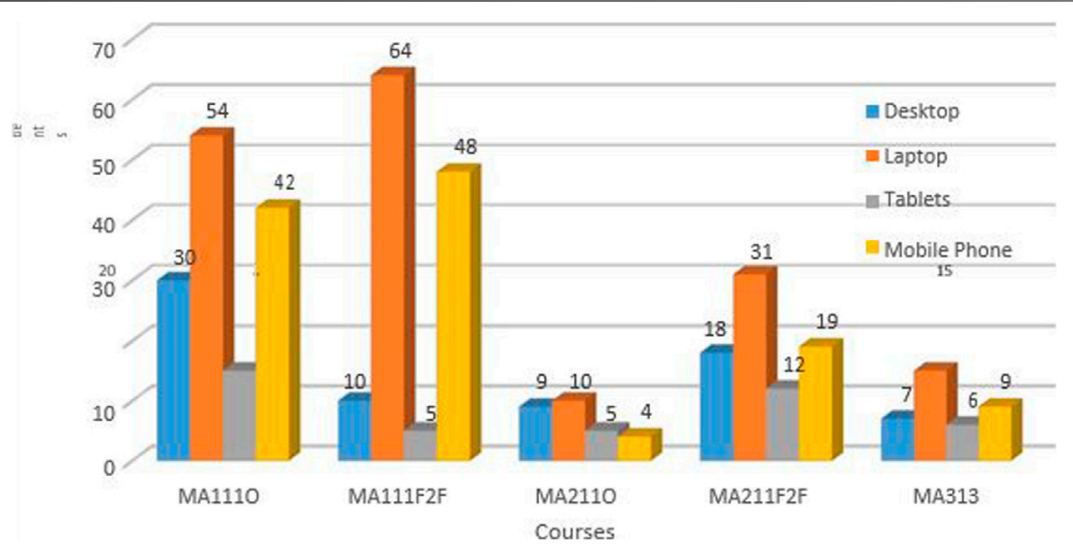

FIGURE 2 | Devices used by the students.

TABLE 6 | Students' perspective on the selected ATs commonly used at USP.

\begin{tabular}{|c|c|c|c|c|c|}
\hline \multirow[t]{2}{*}{ Variable } & MA111F & MA1110 & MA211F & MA2110 & MA313F \\
\hline & Mean & Mean & Mean & Mean & Mean \\
\hline Lecture capture & 4.18 & 4.47 & 4.04 & 3.96 & 4.28 \\
\hline $\mathrm{BBB}$ & 4.47 & 3.83 & 3.79 & 3.40 & 3.82 \\
\hline Satellite tutorial & 4.22 & 3.89 & 3.65 & 4.06 & 3.97 \\
\hline
\end{tabular}

TABLE 7 | Students' perspectives on the ATs.

\begin{tabular}{|c|c|c|c|c|c|c|}
\hline \multirow[t]{2}{*}{ Variable } & \multirow{2}{*}{$\frac{\text { MA313 }}{\text { Mean }}$} & \multirow{2}{*}{$\frac{\text { MA1110 }}{\text { Mean }}$} & \multirow{2}{*}{$\frac{\text { MA111F }}{\text { Mean }}$} & \multirow{2}{*}{$\frac{\text { MA211F }}{\text { Mean }}$} & \multirow{2}{*}{$\frac{\text { MA2110 }}{\text { Mean }}$} & \multirow{2}{*}{$\frac{\text { MA313F }}{\text { Mean }}$} \\
\hline & & & & & & \\
\hline U1 & 4.10 & 4.48 & 4.38 & 4.28 & 3.42 & 4.00 \\
\hline U2 & 4.00 & 4.29 & 4.29 & 3.97 & 3.50 & 3.95 \\
\hline U3 & 4.05 & 4.36 & 4.33 & 4.00 & 3.42 & 4.00 \\
\hline U4 & 4.00 & 4.36 & 4.35 & 4.03 & 3.42 & 3.95 \\
\hline U5 & 4.05 & 4.38 & 4.27 & 4.17 & 3.50 & 4.05 \\
\hline U6 & 3.95 & 4.36 & 4.23 & 4.17 & 3.50 & 3.90 \\
\hline U7 & 3.95 & 4.40 & 4.21 & 4.08 & 3.50 & 3.95 \\
\hline U8 & 3.95 & 4.33 & 4.25 & 3.94 & 3.33 & 4.00 \\
\hline U9 & 4.15 & 4.38 & 4.31 & 4.11 & 3.92 & 3.90 \\
\hline U10 & 4.10 & 4.40 & 4.27 & 3.94 & 3.83 & 3.95 \\
\hline
\end{tabular}

mathematics in their preferred style and pace, improved their performance in mathematics, and reduced the negativity toward mathematics as a subject. The mathematics students' perceptions in this study are similar to the claims made by [11, 50, 51, 52].

For MA211O, the student perception for BBB was more on the neutral end. The exposure to this AT and its guidance and valid contributions toward learning might not be clear to the students. According to [21], students' perception of a given technology hugely depends on the awareness and competency of the students toward it. Since BBB has been formally introduced quite recently in courses, its usage is still in the infancy stage.

2. Student perspective on any Assistive Technology for MA111O, MA111F, MA211O, and MA211F
The students' perception of the ATs utilized for this study staged around "agreed" with a few "neutral" feelings. Students significantly positively perceived that the use of ATs for learning mathematics is important; they enhance communication and collaboration, make the content more attractive for learning, enhance the learning methodologies in mathematics, and make the concept in mathematics better to understand. Furthermore, the ATs help students to learn concepts using their learning preferences, help students to learn concepts using their learning style, improve student performance in mathematics, and reduce the negativity toward mathematics as a subject.

\section{DISCUSSION}

In the current study, student perception was evaluated regarding the use of the following ATs in their mathematics learning: lecture capture, satellite tutorial, BBB, OMDT, tablet, mobile device, interactive whiteboard, simulation games, mathematics software, and online videos. Since the results show that the students have used online videos more than lecture capture, it can be effectually stated that the students perceive online videos as more effective for their learning. This is aligned with other research that has been carried out on the use of ATs whereby the participants have indicated that online videos and lecture capture were good learning tools [52]. Greater numbers of students have used online videos, lecture capture, and mobile devices; therefore, it can be concluded that the students were more aware and had relevant competencies about these ATs. The overall mean for the most commonly used AT was online videos followed by mobile phones and then lecture capture. The results from the study are in line with related studies in the literature which show that online videos are more popular among students because they are more interactive and more comfortable to understand and follow when compared to the other ATs [50-52]. For the successful implementation of other ATs that are part of this study, the authors of this paper believe that relevant guidelines and training on its usage and effectiveness must be provided to the users. This was gathered from the responses of the students as there were some ATs whose usage was more popular in one course compared 
to the other. The facilitators will also need to show a positive attitude and perception toward these ATs as their behavior will have a direct correlation on the adoption of the ATs by their students [57]. The facilitators must know how to use these ATs and then effectively implement the ATs in their courses with proper guidelines to the students. The students' perception regarding the use of the three most commonly used ATs at USP was also evaluated. The students perceived that the use of lecture capture, satellite tutorial, and $\mathrm{BBB}$ was important, enhanced communication and collaboration, enhanced the learning processes in mathematics, allowed students to learn math in their preferred style and pace, improved their performance in mathematics, and reduced the negativity toward mathematics as a subject. Reflecting on students' perception of the overall use of the different ATs in mathematics courses, the students believed that ATs are important for the learning of mathematics. Moreover, the students have a positive attitude toward using the ATs for their learning purposes as the average rating for each attribute on the Likert scale is 3.5 and above. The use of ATs in mathematics courses tends to make learning more attractive, enhances the learning methodologies in mathematics, and makes the concept in mathematics better to understand. Furthermore, ATs create a sense of self-independent learning and accommodate students' learning preferences. From the current study, it can be deduced that the use of ATs in mathematics education has improved student performance in mathematics and to some extent reduced the negativity toward mathematics as a subject.

\section{CONCLUSION}

The current pandemic has paved the way for increased use of assistive technologies in teaching and learning. At USP, assistive technologies such as lecture capture recordings, virtual tutorial

\section{REFERENCES}

1. Abiatal L, Howard G. Constructivism-led assistive technology: an experiment at a Namibian special primary school. S Afr J Chem Eng (2020) 10: 1-18. doi:10. 4102/sajce.v10i1.794

2. Adebisi RO, Liman NA, Longpoe PK. Using assistive technology in teaching children with learning disabilities in the 21st century. J Educ Pract (2015) 6(24):14-20.

3. Ahmed A. Perceptions of using assistive technology for students with disabilities in the classroom. Int J Spec Educ (2018) 33(1):129-39.

4. Akpan J, Beard L. Assistive technology and mathematics education. Universal J Educ Res (2014) 219-22. doi:10.13189/ujer.2014.020303

5. Alharbi S. Benefits and barriers: incorporating assistive technology in an inclusive setting for primary school students with learning disabilities in language arts. ARJHSS (2016) 1-4. 10.21694/2378-7031.16016

6. Alnahdi G. Assistive technology in special education and the universal design for learning. Turk Online J Educ Technol (2014) 13(2):18-23.

7. Annarumma M, Vitale L, Sessa F, Tedesco I. The reorganization of the family system at the time of covid-19: educational resilience and assistive technologies. Ppc (2020) 14(1):18-26. doi:10.33225/ppc/20.14.18

8. Asebriy Z, Raghay S, Bencharef $O$. An assistive technology for braille users to support mathematical learning: a semantic retrieval system. Symmetry (2018) 1-16. doi:10.3390/sym10110547

9. Audi D. Teaching mathematics using lecture capture technology. EPESS (2017) $6: 1-8$. sessions using $\mathrm{BBB}$, satellite tutorials, OMDT, tablets, mobile devices, interactive whiteboards, simulation games, mathematics software, and online videos have been utilized for teaching and learning mathematics. This study revealed that the two most effectively and frequently used ATs are online videos and lecture capture recordings. The study also revealed that laptops and mobile devices are the most commonly used devices to access the available ATs. Overall, students perceived that the use of ATs for learning mathematics is important since ATs enhance communication and collaboration and foster engaged learning. Finally, ATs ensure that students complete their courses and programs successfully even during crises and emergencies such as COVID-19 pandemic.

\section{DATA AVAILABILITY STATEMENT}

The raw data supporting the conclusions of this article will be made available by the authors, without undue reservation.

\section{ETHICS STATEMENT}

The studies involving human participants were reviewed and approved by FRC at the University of the South Pacific. Written informed consent for participation was not required for this study in accordance with the national legislation and the institutional requirements.

\section{AUTHOR CONTRIBUTIONS}

All authors listed have made a substantial, direct, and intellectual contribution to the work and approved it for publication.

10. Barrett P, Treves A, Shmis T, Ambasz D, Ustinova M. The impact of school infrastructure on learning: a synthesis of the evidence. In International development in focus Washington, United States: World Bank (2019)

11. Bouck E, Satsangi R. Maths assistive technology to support inclusion Bingley, England: Emerald Publishing Limited (2020) p. 1-18.

12. Cavanaugh $\mathrm{T}$. The need for assistive technology in educational technology. Assoc Adv Comput Educ J (2002) 10(1):27-31.

13. Chaudhary K, Chand V, Fehnker A. Double-spending analysis of bitcoin. Available at: https://aisel.aisnet.org/pacis2020/210/

14. Chaudhary K, Dai X, Grundy J. Experiences in developing a micro-payment system for peer-to-peer networks. Int J Inf Technol Web Eng (2010) 5(1):23-42. doi:10.4018/jitwe.2010010102

15. Chiang F-K, Qin L. A Pilot study to assess the impacts of game-based construction learning, using scratch, on students' multi-step equationsolving performance. Interact Learn Environ (2018) 26:803-14. doi:10.1080/ 10494820.2017.1412990

16. Daniel M. A literature review: the effect of implementing technology in a high school mathematics classroom. IJRES (2016) 295-9. doi:10.21890/ijres. 98946

17. Daroni GA, Gunarhadi G, Legowo E Assistive technology in mathematics learning for visually impaired students. Tadris (2018) 3:1-9. doi:10.24042/ tadris.v3i1.2406

18. Fabian K, Topping KJ, Barron IG. Using mobile technologies for mathematics: effects on student attitudes and achievement. Educ Technol Res Dev (2018) 66 1119-39. doi:10.1007/s11423-018-9580-3 
19. Foley AR, Masingila JO. The use of mobile devices as assistive technology in resource-limited environments: access for learners with visual impairments in Kenya. Disabil Rehabil Assist Technol (2015) 10(4):332-9. doi:10.3109/ 17483107.2014.974220

20. Goegan L, Le L, Rioux B, Daniels L. Examining factors that support continued use of assistive technologyby postsecondary students with disabilities. Can J New Scholars Educ (2019) 1-14.

21. Gouia-Zarrad R, Gunn CL. Students' perceptions of lecture capture in University math classes for engineers. In Advances in science and engineering technology international conferences (ASET) Abu Dhabi, United Arab Emirates: IEEE (2018)

22. Hodges C, Moore S, Lockee B, Trust T, Bond A. The difference between emergency remote teaching and online learning. Available from: https:// ereducauseedu2020.

23. Iji C, Abah J, Anyor J. Impact of cloud services on students' attitude towards mathematics education in public universities in benue state, Nigeria. J Res Educ Sci (2017) 228-44.

24. Kamaghe JS, Luhanga ET, Kisangiri M. The challenges of adopting M-learning assistive technologies for visually impaired learners in higher learning institution in Tanzania. Int J Emerg Technol Learn (2020) 15(1):140-51. doi:10.3991/ijet.v15i01.11453

25. Kiru EW, Doabler CT, Sorrells AM, Cooc NA. A synthesis of technologymediated mathematics interventions for students with or at risk for mathematics learning disabilities. J Spec Educ Technol 33 (2017) 111-23. doi:10.1177/0162643417745835

26. Klemes J, Epstein A, Zuker M, Grinberg N, Ilovitch T. An assistive computerized learning environment for distance learning students with learning disabilities. Open Learn J (2006) 21(1):19-32. doi:10.1080/02680510500468062

27. Kumar R, Sharma K, Assaf M, Sharma B, Naidu S. Development of an assistive tongue drive system for disabled individuals Nadi, Fiji: Springer.

28. Li K, Li Y, Franklin T. Preservice teachers' intention to adopt technology in their future classrooms. J Educ Comput Res (2016) 54(7):946-66. doi:10.1177/ 0735633116641694

29. Maich K, Tv R, Woods H, Brochu K. Teachers' perceptions of the need for assistive technology training in Newfoundland and Labrador's rural schools. Can J Learn Technol (2017) 43(2):1-26.

30. Mohmmed A, Khidhir B, Nazeer A, Vijayan V. Emergency remote teaching during Coronavirus pandemic: the current trend and future directive at Middle East College Oman. Innov Infrastruct Solut (2020) 5: 72. doi:10.1007/s41062020-00326-7

31. Nordmann E, McGeorge P. Lecture capture in higher education: time to learn from the learners (2018) https://psyarxiv.com/ux29v/.

32. Rajkumar R. Assistive technology for mathematics learning disabilities (Dyscalculia) (2016) National Seminar on Recent Trends in Special Education.

33. Reddy E, Reddy P, Sharma B, Reddy K, Khan M. Student readiness and perception to the use of smart phones for higher education. Nadi, Fiji: IEEE (2016)

34. Reddy E, Sharma B. Mobile learning perception and attitude of secondary school students in the pacific Islands. Yokohama, Japan: Association for Information Systems (2018)

35. Reddy E, Sharma B, Reddy P, Dakuidreketi M. Mobile learning readiness and ICT competency: a case study of senior secondary school students in the Pacific Islands. Nadi, Fiji: IEEE (2017)

36. Reddy P, Chaudhary K, Sharma B, Chand R. The two perfect scorers for technology acceptance. Educ Inf Technol (2020) 2020: 1-23. doi:10.1007/ s10639-020-10320-2

37. Reddy P, Sharma B, Chandra S. Student readiness and perception of tablet learning in higher education in the pacific- a case study of Fiji and Tuvalu. J Cases Inf Technol (2020) 22: 52-69. doi:10.4018/jcit.2020040104

38. Reddy P, Sharma B, Chaudhary K. Measuring the digital competency of freshmen at a higher (2020) Available at: https://aisel.aisnet.org/pacis2020/6/.

39. Reddy P, Sharma B, Chaudhary K. Digital literacy. Int J Technoethics (2020) 11(2):65-94. doi:10.4018/ijt.20200701.oal

40. Sadaf A, Newby TJ, Ertmer PA. An investigation of the factors that influence preservice teachers' intentions and integration of Web 2.0 tools. Educ Technol Res Dev (2016) 64(1):37-64. doi:10.1007/s11423-015-9410-9

41. Sharma B, Fonolahi A, Bali A, Narayan S. The online mathematics diagnostic tool for transformative learning in the Pacific. Cases Smart Learn Environ (2018) 63-80. doi:10.4018/978-1-5225-6136-1.ch005
42. Sharma B, Jokhan A, Kumar R, Finiasi R, Chand S, Rao V. Use of short message service for learning and student support in the Pacific region. In Handbook of mobile teaching and learning Berlin, Heidelberg: Springer (2015)

43. Sharma B, Kumar R, Rao V, Finiasi R, Chand S, Singh V. A mobile learning journey in pacific education. In Mobile learning in higher education in the AsiaPacific region: harnessing trends and challenging orthodoxies Singapore, Singapore: Springer (2017) 581-605.

44. Sharma B, Lauano FIJ, Narayan S, Anzeg A, Kumar B, Raj J. Science teachers accelerated programme model: a joint partnership in the Pacific region. Asia Pac J Teach Educ (2018) 46:38-60. doi:10.1080/1359866x.2017.1359820

45. Sharma B, Nand R, Mohammed N, Reddy E, Narayan S, Reddy K. Smart learning in the Pacific: design of new pedagogical tools. Wollongong, New South Wales, Australia: IEEE International Conference on Teaching, Assessment, and Learning for Engineering, (2018c)

46. Sharma B, Nand R, Naseem M, Reddy EV. Effectiveness of online presence in a blended higher learning environment in the Pacific. Stud High Educ (2019) 45: 1547-65. doi:10.1080/03075079.2019.1602756

47. Sharma B, Reddy P. Effectiveness of tablet learning in online courses at university of the South Pacific. Nadi, Fiji: IEEE (2016)

48. Soetan A, Onojah A, Alaka T, Aderogba A. Hearing impaired students' selfefficacy on the utilization of assistive technology in federal college of education (special) oyo. Int J Cross-Disciplinary Subj Educ (2020) 11:4245-52. doi:10. 20533/ijcdse.2042.6364.2020.0519

49. Sokhulu LH. Students' experiences of using digital technologies to address their personal research needs during the COVID-19 lockdown. Afr Ident (2020) 18(3):1-17. doi:10.1080/14725843.2020.1801384

50. Sung R, Lin S, Lin C. Collaborative assistive technology in mathematics learning for students with special needs. Tokyo, Japan: Asian Conference on Education (2018)

51. Svela A, Nouri J, Viberg O, Zhang L. A systematic review of tablet technology in mathematics education. Int J Interact Mobile Technol (2019) 138-58. doi:10. 3991/ijim.v13i08.10795

52. Tella A, Mutula SM. Gender differences in computer literacy among undergraduate students at the University of Botswana: implications for library use. Malays J Libr Inf Sci (2008) 13(1):59-76.

53. Alwis D. Universities shut down across south and southeast Asia. (2020) Available at: https://www.universityworldnews.com/post.php?story=2020032008521144 (Accessed October 15, 2020).

54. The University of the South Pacific. COVID-19 pandemic management plan (2020) Available at:https://www.usp.ac.fj/fileadmin/files/services/prop_facil/ OHS/COVID-19/Pandemic- Plan-2020/COVID-19-USP-Response-Plan-2020. pdf (Accessed October 15, 2020).

55. Wairimu C, Chomba J, Awori B. Factors influencing the use of assistive technology in teaching mathematics to learners with visual impairements in special primary schools in Kenya. Acad Res Int (2018) 154-61.

56. Warner S, Kaur A. The perceptions of teachers and students on a 21st century mathematics instructional model. Int Electron J Math Educ (2017) 193-215. doi:10.29333/iejme

57. Wilkowska W, Leonhardt $\mathrm{T}$, Leonhardt $\mathrm{M}$, Ziefle $\mathrm{M}$. Learning and collaboration technologies designing learning experiences. In: Technology-enhanced learning: correlates of acceptance of assistive technology in collaborative working setting New York, NY: Springer (2019) 423-39.

58. Zain N, Mahmud M. Acceptance and readiness of mobile leaning integration among teachers of dyslexic students: a preliminary study. Int J Multimed Appl (2018) 157-68. doi:10.5121/ijma.2018.10613

Conflict of Interest: The authors declare that the research was conducted in the absence of any commercial or financial relationships that could be construed as a potential conflict of interest.

Copyright (C) 2021 Reddy, Reddy, Chand, Paea and Prasad. This is an open-access article distributed under the terms of the Creative Commons Attribution License (CC BY). The use, distribution or reproduction in other forums is permitted, provided the original author(s) and the copyright owner(s) are credited and that the original publication in this journal is cited, in accordance with accepted academic practice. No use, distribution or reproduction is permitted which does not comply with these terms. 